\title{
В.П. ЧУМАКОВА
}

\section{ТИПЫ «КУЛЬТУРНОЙ ПРЕДРАСПОЛОЖЕННОСТИ КОММУНИКАЦИИ» СОВРЕМЕННЫХ СТУДЕНТОВ: ИНТЕРПРЕТАЦИЯ КОНЦЕПЦИИ ГЕРБЕРТА МАРШАЛЛА МАКЛЮЭНА}

\begin{abstract}
Статья посвящена изучению типов «культурной предрасположенности коммуникации» современных студентов на основе концепции медиа канадского ученого Герберта Маршалла Маклюэна, которая становится актуальной в эпоху Интернета и мобильных технологий. Опираясь на теорию Маклюэна и его последователей, автор показывает, что «культурная предрасположенность коммуникации» усиливает те или иные практики работы с информацией в ходе получения образования. Теоретические рассуждения автор иллюстрирует наблюдениями из своей педагогической практики.

Ключевые слова: культурная предрасположенность коммуникации, Герберт Маршалл Маклюэн, современные студенты, практики работы с информацией, книжная культура, культура «второй устности», «глобально-сетевая» культура, медиасреда.
\end{abstract}

$\mathrm{P}$ азвитие средств коммуникации, в частности распространение Интернета, связано с трансформацией института высшего образования. По данным TNSRussia, в мае 2014 года доля пользователей Интернета в России составила $72 \%$ от всего населения страны, при этом доля учащихся россиян, так или иначе пользующихся Интернетом, достигла практически своего максимума $99 \%$ [1]. Тем не менее, на данном этапе нельзя говорить о единообразии в трансформации общества, как это делали теоретики массового общества. Современное общество дробится на многочисленные сообщества, по-разному адаптирующиеся к новым технологиям [2]. То же самое можно сказать и о современных студентах: некорректно рассматривать их исключительно как вовлеченных пользователей Интернета, которые мыслят в формате сообщений в социальных сетях. Более близкое знакомство с современными студентами позволяет сделать вывод, что они демонстрируют разные типы восприятия и понимания информации, обусловленные принадлежностью студентов к разным культурам потребления и пользования медиа.

В данной статье предлагается проанализировать три основных типа восприятия и понимания информации, выделяемых на основании того, к потреблению и использованию каких медиа индивид больше тяготеет:

- чтению линейных по организации текстов (классическая книжная и журнальная продукция);

- к просмотру аудиовизуального контента (кино, телевидение);

- к интерактивному электронному общению и чтению гипертекстов.

Как представляется, идеи канадского ученого Герберта Маршалла Маклюэна (1911-1980), предложившего теорию трансформации средств коммуникации, составляют теоретическую основу для такой дискуссии. Собственно, развитие глобальных информационно-сетевых технологий вызвало «ренессанс» идей Маклюэна, которые - парадоксально, но факт, оказались более понятны и актуальны в нашу эпоху, нежели в XX столетии [3]. Сам Маклюэн уделял пристальное внимание вопросам трансформации институтов образования в эпоху электронных средств коммуникации.

Подход Маклюэна интересен и полезен также своей гуманистической направленностью. Ученый во всех своих работах пытается понять людей, пользующихся высокими технологиями [4]. Хотя Маклюэн, отмечая, что современный ему человек не замечает воздействия медиасреды [5, c. 366], продвигал идею развития медиаграмотности [6] как один из важнейших способов, позволяющих человеку оставаться человеком в мире электронных коммуникаций $[5$, c. 8]. Маклюэн подвергался критике и как неолуддист за то, что видел негативные последствия распространения электронных медиа $[7$, р. 3], и в то же время критиковали как проповедника разрушительных технологий [8]. И те, и другие обвинения оказываются беспочвенными при глубоком знакомстве с работами ученого. Главное, к чему стремится Маклюэн, это объективность в описании «нового мира», который создают «новые медиа».

\section{Медиа в понимании Г.М. Маклюэна}

С точки зрения М. Маклюэна, в качестве медиа можно рассматривать всё, что создал человек (включая устную речь), поскольку всё это служит посредником между внешним миром и внутренним миром человека. «Нет разницы что понимать под артефактами или медиа - “аппаратные сред- 
ства" ("hardware") материальной природы, такие как кегли и клюшки или вилки и ложки или инструменты, устройства и машины, железные дороги, космическое оборудование, радио, компьютеры и т. д.; или объекты “программной" ("software") природы, такие как теории или законы науки, философские системы, лекарства или даже болезни в медицине, формы и стили живописи, поэзии, драматургии, музыки и т. д. Все они равнозначно артефакты, равнозначно созданы человеком, равнозначно поддаются анализу, равнозначно вербальны в своей структуре» $[9$, р. 3].

При этом медиа - это не содержание коммуникации, но те формы, без которых это содержание не будет существовать в социальном мире. Медиа моделируют то, как передаваемая информация воспринимается и понимается, и в силу этого они первичны в социальном взаимодействии. Идея медиа как формы заключена в известной формуле ученого: («средство коммуникации есть сообщение») «the medium is the message» [5, c. 10], которая говорит о том, что форма, выбранная, например, для передачи знаний, влияет на то, как эти знания будут восприняты, поняты и усвоены. Маклюэн описывает эксперимент, проведенный в Университете Торонто: «Четырем случайно набранным группам университетских студентов давалась одновременно одна и та же информация о структуре дописьменных языков. Одна группа получала ее по радио, другая - по телевидению, третья - из лекции, а четвертая ее читала» [5, с. 356]. (Опустим детали эксперимента, все они имели цель увеличить его чистоту.) В итоге, после нескольких волн экспериментов исследователи пришли к выводу, что при передаче одной и той же информации эффект разных средств коммуникации значимо различается.

Но если в эксперименте то или иное средство коммуникации было навязано студентам, то в жизни множество факторов определяют те медиа, которые студент будет потреблять и использовать. Маклюэн развивает эту мысль, говоря о том, что использование и потребление разных типов медиа связано с разными типами медиасред. Медиасреда, по Маклюэну, - это совокупность средств коммуникации, которыми пользуется индивид. Медиасреда находится в постоянной трансформации - «новые» средства коммуникации все время появляются, а «старые» вытесняются и уходят на второй план [9, р. 7, 99, 227]. Анализируя механизмы этой трансформации, Маклюэн пользуется концепцией «фигура-фон», заимствованной из теории гештальта $[9$, p. 5]. Смысл этой концепции состоит в том, что восприятие индивида выделяет в окружающем мире отдельные образы, однако не способно воспринять их в совокупности. Одни образы становятся «фигурой», а другие образуют «фон» для восприятия этой фигуры. Накладывая теорию гештальта на представления о медиасреде, Маклюэн доказывает, что, несмотря на постоянное увеличение числа средств коммуникации, доступных человеку, у индивида всегда есть медиа, практики пользования которыми определяющие, то есть они образуют «фигуру», а есть медиа, образующие «фон». Например, индивид может уметь читать и даже иногда это практиковать, но основной способ получения информации для него - просмотр телепередач; тогда чтение будет «фоном», а телевизор «фигурой». Или же индивид может иногда смотреть телевизор, но в основном проводит время в социальных сетях: тогда телевидение - это «фон», а социальные сети - «фигура». Разные медиасреды будут по-разному обусловливать восприятие и понимание информации.

При этом для обычного человека, в понимании Маклюэна, особенности медиасреды зачастую остаются незаметными, потому что он, как правило, не выходит за ее пределы. Маклюэн сравнивает такого пользователя с рыбой, которая обнаружит, что жила в воде, только если ее выбросит на сушу [10].

Еще одно, более важное наблюдение Маклюэна о трансформации медиасреды человека состоит в том, что нет ничего принципиально нового, все «новые» медиа так или иначе возвращают практики прошлого. «Новые медиа, - пишет Маклюэн, - это не способы соединения нас со старым "реальным" миром, они и есть новый мир, и они по-разному переформатируют то, что осталось от старого» [11]. То есть любая «новая» практика использования и потребления медиа имеет аналог в истории.

\section{Три базовых типа восприятия и понимания информации студентами}

Изучая медиасреды, Маклюэн выделяет три базовых глобальных медиасреды в зависимости от того, что становится фигурой: устная речь - «галактика племенного человека»; печатная книга - «галактика Гутенберга»; электронные средства коммуникации, преимущественно телевидение - «галактика нового племенного человека» $[5 ; 10 ; 12 ; 13]$, которая может быть охарактеризована как «вторая устность» $[4 ; 14]$.

Маклюэн ушел из жизни в 1980 году, не застав социальные сети и многое другое, хотя многое предсказал. Тем не менее, его «галактика нового племенного человека» больше связана с потреблением таких медиа, как фотография, кино, радио и телевидение как апогей той эпохи. Современный исследователь медиа Джозеф Дугган предложил выделить в электронной эпохе отдельно «галактику Цукерберга» [15], отделив тех, для кого «фигура» - это социальные сети, от тех, для кого эту роль играет телевидение. Также предлагается сделать и нам, выделив при этом три основных типа студентов, которые могут тяготеть к той или иной «галактике»: «Гутенберга», «второй устности» или «Цукерберга» ${ }^{1}$. Склонность индивида к той или иной «галактике» определяет его «культурную предрасположенность коммуникации» («bias of communication»). Этот термин Маклюэн заимствовал у своего учителя Гарольда Инниса [16], который называл

\footnotetext{
1 Здесь не рассматриваются студенты из «галактики племенного человека», так как таковые (то есть не знающие грамоты) практически отсутствуют в вузах сегодня. - B.Ч.
} 
так паттерны восприятия и понимания информации, конструирования реальности на ее основе и т. д. [17].

Ниже представлено описание трех типов, проиллюстрированное наблюдениями автора статьи, полученными в процессе преподавания. Автору приходилось работать с разными учебными группами, и студенты из этих групп имели разную «культурную предрасположенность коммуникации». Безусловно, нельзя редуцировать личность до типа, и каждый человек в силу своей индивидуальности представляет собой неповторимое сочетание характеристик. Тем не менее, в научных целях можно исходить из предположения, что у каждого студента превалирует склонность к одному из названных типов, а остальными отклонениями можно пренебречь. Поэтому в данной статье будут описаны три типа предрасположенности на примере «идеальных типов», сконструированных на основании наблюдений. Стоит отметить, что изложенное ниже представляет собой результаты включенного наблюдения, возникавшего в ходе работы, но никак не целенаправленного использования студентов для исследования, что противоречило бы этическому кодексу социолога.

Ключевое различие «книжной», «второй устной» и «глобально-сетевой» культуры получения знаний состоит в разном восприятии изучаемой действительности. Что касается пространства, в котором располагаются изучаемые объекты, то студент книжной культуры видит это пространство как структурированное и однородное [9]. Так, например, при выполнении заданий на подготовку аргументов в защиту той или иной позиции «книжные» студенты стремятся обобщить всё в виде схемы, когнитивной карты. Представители «второй устной» культуры, безусловно, также могут структурировать информацию, но им это не требуется для ее понимания и усвоения. «Новым племенным людям» сложнее выявлять основания для объединения тех или иных аргументов в группы, так как каждый из них они рассматривают как самодостаточное явление [14]. Студенты «галактики Цукерберга» привыкли не к линейному тексту, а к гипертексту со множеством переходов [15], что не позволяет представить себе всю структуру текста, поскольку индивид живет в мире, карта которого никому целиком не известна, поэтому и рисовать ее не всегда имеет смысл. Нелинейное восприятие реальности, формируемой гипертекстами, подразумевает, что индивид допускает существование альтернативных точек зрения как данность, но при этом все равно вынужден выбирать свою позицию - то есть он заранее знает, что никогда не будет объективным.

Таким образом, представители глобально-сетевой культуры конструируют реальность, в которой априори невозможно получить всю информацию о том или ином объекте, всегда есть недостаток информации, вызванный ее переизбытком - человеческих возможностей недостаточно, чтобы охватить весь поток. Это принципиально отличается от подхода книжного человека, в восприятии которого анализируемые объекты можно полностью изучить. Представители обоих типов сталкиваются с трудностями в процессе получения образования. Студент книжного типа может быть «выбит из колеи» переизбытком информации, а студент «галактики Цукерберга» хоть и «свободно плавает» в этой информационной среде, тем не менее, нуждается в фильтрации информационных потоков. Эту функцию может взять на себя преподаватель. Часто студенты сами просят сориентировать их в информационном пространстве. «Новым племенным» студентам доступная информация воспринимается как вся существующая. «Вторая устная» культура не предполагает сохранения данных в каталогах, библиотеках, архивах, таким образом, ее представителю сложно представить, что помимо того, что он видит и слышит в данный момент, есть еще что-то невидимое и неслышимое здесь и сейчас [18]. Поэтому такие студенты часто ограничиваются подготовкой к экзамену по конспектам или высланным преподавателем презентациям, не прибегая к первоисточникам. Им кажется, что в них не встретится ничего нового. Мимесис, подражание - основа получения знаний в устной культуре [9], и, повторяя за преподавателем, студенты могут пребывать в полной уверенности, что именно так и нужно. Здесь преподаватель может помочь через развенчание этого мифа.

Если говорить о конструировании времени, то восприятие информации о прошлом и прогнозирование будущего также различаются у студентов, относящихся к разным типам культурной предрасположенности. 0бращаясь к истории, студенты «галактики Гутенберга» хорошо справляются со встраиванием тех или иных событий, персонажей в развивающийся процесс [12], видят причинно-следственные связи, так как именно книга формирует препозиционное мышление, которое вытесняется репрезентативным в культуре «второй устности» [19]. Для «нового племенного человека» реальность конструируется из двух времен - настоящее время и «идеальный мир» вечности, в котором пребывают те или иные мифологические образы [20]. Студенты, относящиеся к этой культуре, могут включать в реальное историческое прошлое вымышленных персонажей. Студенты «галактики Цукерберга» также часто соединяют при конструировании прошлого существующее и вымышленное, но для них истинность событий не имеет значения - история в их прочтении представляет собой разрозненный набор событий и персон, никак не привязанных к единой системе координат. И прошлое, и будущее для представителей «глобально-сетевой» культуры - альтернативные миры $[21 ; 22]$. Поэтому им легче других рассуждать о будущем, строить прогнозы, но их будущее обычно мало связано с существующей реальностью и больше походит на реальность альтернативную. «Глобально-сетевые» люди видят множество альтернатив, но не выстраивают их в строгую последовательность. «Новые племенные» студенты чаще затрудняются, когда им требуется подумать о будущем, так как культура «второй устности», как сказано выше, 
не предполагает конструирования образов прошлого и будущего. В реальности «галактики Цукерберга» всё тоже происходит «здесь и сейчас» [23], но в ней есть аналоги «будущего» и «прошлого», представленные как альтернативные миры, между которыми нет линейной связи, а есть гиперссылки. У «новых племенных» людей есть только настоящее и «идеальный мир», поэтому их прогнозирование часто сводится к описанию «идеального мира». Студенты книжной культуры конструируют будущее как продолжение настоящего, потому создание альтернативных миров им часто недоступно.

Как отмечено выше, основной способ получения знаний в культуре «второй устности» - мимесис, то есть подражание. Для него характерна эмоциональная вовлеченность в изучаемую проблему, переживание ее [14]. Глобально-сетевая культура децентрализует процесс коммуникации в ходе освоения знаний, основной формой, органичной для этой культуры, оказывается игра, в которой индивид может примерить на себя разные роли. Книжный человек более склонен к умозрительному моделированию тех или иных ситуаций [5], но менее склонен к проигры- ванию ролей, таким студентам эта форма занятий часто кажется бессмысленной и несерьезной.

Если связать эти типы культурной предрасположенности с типами мышления, которые выделяют психологи, то очевидно, что представителям книжной культуры чаще свойственен абстрактно-логический тип мышления [24], собственно, этот тип мышления и формируется благодаря книге, как отмечает ученик Маклюэна Нейл Постман [19]. Телевизионная культура «отбрасывает» общество в «детство» [19], и представителям культуры «второй устности» более свойственно мышление наглядно-действенное и конкретно-предметное [24]. Что касается глобально-сетевой культуры, то здесь можно наблюдать возвращение абстрактного мышления, но оно уже становится «альтернативным»индивид смотрит на явления с разных сторон, порой противоположных. Так как информации априори недостаточно, решения принимаются в условиях нехватки данных, возрастает значимость интуитивного мышления.Таким образом, можно обобщить выше сказанное в виде таблицы.

\section{Свойства типов «культурной предрасположенности коммуникации»}

\begin{tabular}{|l|}
\hline \multicolumn{1}{|c|}{ Процессы } \\
мышления
\end{tabular}

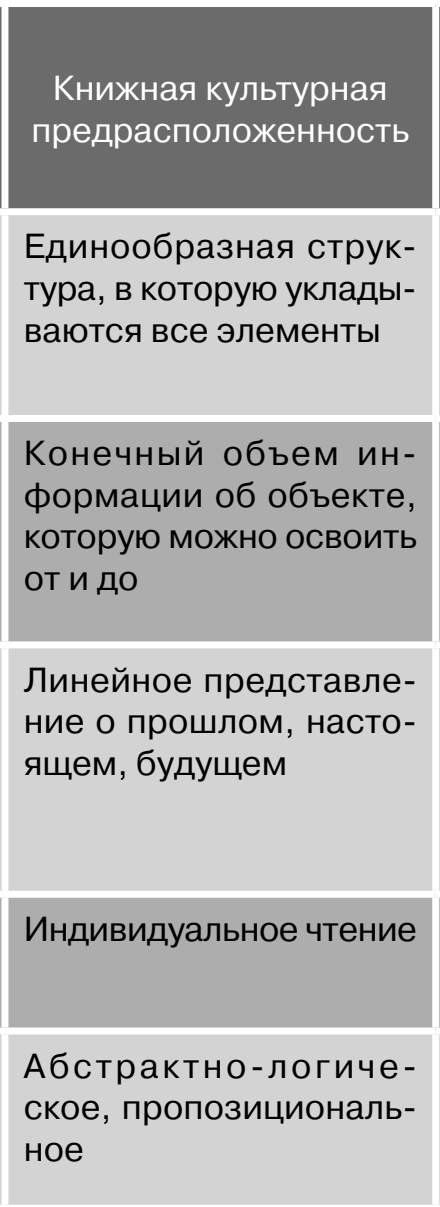

\begin{tabular}{l}
\multicolumn{1}{c}{ Культурная } \\
предрасположенность \\
«второй устности» \\
Каждый элемент - отдель- \\
ный, сам по себе
\end{tabular}

Доступная информация воспринимается как вся существующая

Есть только настоящее и «идеальный» мир образов, мифов

\section{Мимезис}

Наглядно-действенное, конкретно-предметное, репрезентативное

«Глобально-сетевая»
культурная
предрасположенность
Бесконечное число аль-
тернативных структур и
элементов, разветвле-
ний
Априорная невозмож-
ность охватить всю
имеющуюся информа-
цию об объекте

Есть настоящее и бесконечное число альтернативных времен, нелинейно друг с другом соединенных

Игра

Интуитивное, альтернативное 
Как мог заметить читатель, в представленной статье минимальна критика типов «культурной предрасположенности коммуникации», отличных от книжного, хотя распространение этих типов зачастую становится барьером при общении преподавателя и студентов. Мало того, современные высшие учебные заведения, несмотря на значительные изменения, произошедшие в сфере коммуникации (переход на общение по электронной почте, создание учебных групп в социальных сетях, проведение занятий через видеоконференции, появление электронных систем поддержки образовательного процесса и т. д.), так или иначе, продолжают традиции книжной культуры «галактики Гутенберга». Мы всё так же опираемся на книги, всё так же предлагаем линейное освоение дисциплин, всё так же принимаем экзамены, используем защиту дипломной работы как итоговое испытание и т. д. Количество же студентов, относящихся к культуре «второй устности» и «глобально-сетевой», пока что только увеличивается. 0днако цель этой статьи - не подвергнуть критике происходящее и выступить за отказ от пользования новыми технологиями. Ее цель в том, чтобы показать, что понимание другого типа культуры может облегчить коммуникацию между преподавателем и студентами. Как можно заключить из выше сказанного, тяжелее всего последовательное образование дается представителям культуры «второй устности», которая формируется телевидением. Студенты, «выросшие» на телевизионной культуре, в скором будущем должны уступить место студентам, воспитанным в «глобально-сетевой» культуре. Эта культура, хоть и значительно отличается от книжной, тем не менее, возвращает из прошлого интерес к знанию, составляющий ценностное ядро книжной культуры, только на новом уровне. Вместо стремления к единому представлению о мире возникает культура, допускающая существование альтернатив. При позитивной адаптации к подобной медиасреде, умении фильтровать лишнюю информацию студент будущего с такой «культурной предрасположенностью коммуникации» может быть перспективным для института высшего образования. Можно сказать, что на данном этапе исторического развития новые технологии проходят стадию «аттракциона», как было с их предшественниками, однако это не значит, что все последующие поколения также будут пользоваться Интернетом преимущественно для развлечения.

\section{Список литературы}

1. WebIndexReport, Май 2014 [Электронный ресурс]. - Peжим доступа: http://www.tns-global.ru/services/media/ media-audience/internet/information/

2. Полудина В.П. Избыточность и информационный шум в социальной коммуникации (к определению понятия) // Социальные коммуникации: универсум профессиональной деятельности. - СПб.: Скифия-принт, 2011.
3. Meyrowitz J. Morphing McLuhan: Medium Theory for a New Millennium // Proceedings of the Media Ecology Association. - 2001. - Vol. 2. - P. 8-22.

4. Lamberti E. Marshall McLuhan's Mosaic: Probing the Literary Origins of Media Studies. - Toronto: University of Toronto Press, Kindle Edition, 2012.

5. Маклюэн М. Понимание медиа: внешние расширения человека. - М.: Кучково поле, 2007.

6. Маклюэн М. Интервью для Playboy [Электронный ресурс]. Режим доступа: http://www.mcluhan.ru/articles/marshallmaklyuen-intervyu-dlya-playboy-ch-1/

7. Liss J. The Heat and the Light: Towards a Reassessment of the Contribution of H. Marsall McLuhan // Canadian Journal of Communication. - Winter, 1989. - № 14. - P. 1-21.

8. Дебор Г.Э. Комментарии к обществу спектакля [Электронный ресурс]. - Режим доступа:http://avtonom.org/old/lib/theory/ debord/comments.html?q=lib/theory/debord/comments.html

9. McLuhan M., McLuhan E. Laws of Media: The New Science . Toronto: University of Toronto Press, 1992.

10. Маклюэн М., Фиоре К. Война и мир в глобальной деревне. М.: АСТ; Астрель, 2012.

11. McLuhan M. Counterblast 1954 Edition / foreword by T. Gordon, afterword by E. Lamberti // Transmediale: festival for art and digital culture. - Berlin, 2011.

12. Маклюэн М. Галактика Гутенберга. Становление человека печатающего. - М.: Академический проект, 2005.

13. McLuhan M., Fiore Q. The Medium is the Message. - Penguin Books, 1996.

14. Ong W. Orality and Literacy: The Technologizing of the Word (30th Anniversary Edition). - Routledge, 2012.

15. Duggan J.P. The Zuckerberg Galaxy. — Kindle Edition. - 2011.

16. Onufrijchuk R.F. Introducing Innis/McLuhan concluding: the Innis in McLuhan «system» // The Australian Journal of Media \& Culture. - 1993. - Vol. 7, № 1.

17. Innis $H$. The Bias of Communication. - Toronto: University of Toronto Press, 1951.

18. McLuhan M., Carpenter E. Acoustic Space // Explorations in Communication: An Anthology / ed. by H.M. McLuhan, E.S. Carpenter. - Boston: Beacon Press, 1960.

19. Postman N. The Disappearance of Childhood: Redefining the Value of School. - New York: Vintage Books, 1994.

20. Новикова А.А., Чумакова В.П. Советские фильмы в новой медиасреде: идеализация или дискредитация представлений о прошлом // Обсерватория культуры. - 2014. - № 2. C. $61-67$.

21. Meyrowitz J. The Rise of Glocality: New Senses of Place and Identity in the Global Village (2004) [Электронный ресурс]. - Режим доступа: http://www.fil.hu/mobil/2004/ meyrowitz_webversion.doc>

22. Meyrowitz J. From Tribal to Global: A Brief History of Civilization from a McLuhanesque Perspective // The Legacy of McLuhan. - Hampton Press, 2005. - P. 35-43.

23. Rushkoff D. Present Shock: When Everything Happens Now. Kindle Edition, 2013.

24. Гальперин П.Я. 0 методе поэтапного формирования умственных действий [Электронный ресурс] // Вопросы психологии. — 1969. — № 1. - Режим доступа: https://sites.google. com/site/nechaevsite/problems/pedagogical/galperin-p-2 